\title{
Pengaruh Return on Equity dan Earning Per Share terhadap Harga Saham pada Sektor Komponen dan Otomotif yang Terdaftar di Bursa Efek Indonesia
}

\author{
Arie Firmansyah \\ Dosen Program Studi Administrasi Keuangan, \\ Politeknik Piksi Ganesha Bandung \\ Email : firmansyah.arie26@gmail.com, \\ Arie.Firmansyah@piksi-ganesha-online.ac.id
}

\begin{abstract}
Abstrak-Tujuan dalam penelitian ini adalah bagaimana pengaruh ROE dan EPS terhadap harga saham perusahaan ban pada sektor otomotif dan komponen yang terdaftar di Bursa Efek Indonesia.Sampel dalam penelitian ini adalah perusahaan ban pada sektor otomotif dan komponen yang terdaftar di Bursa Efek Indonesia selama periode 2007-2016 dengan jumlah sampel perusahaan sebanyak 3 perusahaan, secara keseluruhan jumlah data yang dianalisis adalah sebanyak 30 data. Metode pengumpulan data dalam penelitian ini adalah metode tidak langsung, yaitu data sekunder melalui laporan keuangan. Teknik analisis data yang digunakan adalah analisis regresi linier berganda dengan menggunakan Eviews software 5.0. Hasil penelitian ini menunjukan bahwa secara simultan ROE dan EPS berpengaruh signifikan terhadap Harga saham sebesar $63,82 \%$ dan sisanya sebesar $36,17 \%$ dipengaruhi oleh faktor lain yang tidak diteliti. Dari uji secara parsial ROE dan EPS memberikan pengaruh signifikan positif terhadap Harga Saham.
\end{abstract}

Kata Kunci : ROE, EPS, Harga saham.

\begin{abstract}
The goal in this research is how the influence return on equity and earning per share on the tire company's stock price in the automotive sector and components listed on the Indonesia Stock Exchange. The sample in this research is tire company in automotive sector and components listed in Indonesian Stock Exchange forperiod that is 2007-2016 period with amount of company sample counted 3 company, overall amount of data analyzed is counted 30 data. Data collection method in this research is indirect method, that is secondary data of financial statement. Data analysis technique used is multiple linear regression analysis using Eviews software 5.0 .The results of this study show that simultaneously Return on Equity and Earnings per share have a significant influence on the stock price of $63.82 \%$ and the rest of $36.17 \%$ influenced by other factors not examined in this study. From the partial test the rate of return on equity and earnings per share gives a positive significant effect on Stock Price.
\end{abstract}

Keywords: Return on Equity, Earning per Share, Stock Price.

\section{PENDAHULUAN}

Menurut Tandelilin (2007:236) mengemukakan bahwa "Jika laba perusahaan tinggi maka para investor akan tertarik untuk membeli saham tersebut, sehingga harga saham tersebut akan mengalami kenaikan". Berdasarkan teori diatas jika laba suatu perusahaan meningkat maka akan meningkatkan permintaan saham dan harga saham pun ikut naik. Teori diatas bertentangan dengan fakta yang ada di lapangan. Dari ketiga perusahaan ban yang terdaftar di Bursa Efek Indonesia pada tahun tertentu mengalami sebuah fenomena dimana harga saham perusahaan turun ketika laba bersih meningkat atau sebaliknya.

Berdasarkan fenomena yang telah terjadi peneliti mempunyai keinginan untuk menganalisis faktor kemampuan laba perusahaan yang dapat mempengaruhi harga saham.
Menurut Suad Husnan (2009) tingkat profitabilitas yang mampu dihasilkan oleh emiten akan mempengaruhi tingkat harga saham, kemampuan perusahaan dalam menghasilkan laba untuk lembar saham yang beredar dapat dilihat dalam rasio Earning Per Share (EPS). Menurut Dedi Susilo, Atim Djazuli, Nur Khusniyah (2015) Earning Per Share (EPS) menjadi tolok ukur yang paling sering digunakan oleh investor dalam melihat kinerja perusahaan. Berdasarkan hasil uji hipotesis terlihat bahwa semakin tinggi variabel EPS akan berdampak terhadap peningkatan harga saham. Dan menurut Darmadji dan Fakhruddin (2006) mengemukakan semakin tinggi nilai Earning Per Share tentu saja menyebabkan semakin besar laba sehingga mengakibatkan harga pasar saham naik karena permintaan dan penawaran meningkat. Selain itu menurut Alwi (2003) semakin tinggi Earning Per 
Share suatu perusahaan berarti semakin besar earning yang akan diterima investor dari investasinya tersebut dan bagi perusahaan peningkatan Earning Per Share dapat memberi dampak positif terhadap harga saham dipasar.

Dan menurut Brigham and Houston (2012:150) "ada rasio yang paling penting adalah rasio pengembalian atas modal atau Return On Equity, yang merupakan laba bersih bagi pemegang saham dibagi dengan total ekuitas pemegang saham. Jika Return On Equity tinggi maka harga saham juga cenderung akan tinggi. Dan Menurut Wahyu Yulianto (2015) Return on equity memiliki pengaruh terhadap harga saham karena mencerminkan efisiensi dan efektifitas perusahaan dalam mendapatkan laba bersih berdasarkan jumlah modal yang tersedia. Menurut Danika, Noer Azam, dan Hendro Sasongko (2014) "faktor-faktor fundamental seperti earning per share, book value per share, price earning ratio, return on asset, return on equity, price book value, dan debt equity ratio memberikan pengaruh terhadap harga saham."

Berdasarkan teori dan hasil penelitian terdahulu, mengindikasikan bahwa Return On Equity dan Earning Per Share dapat mempengaruhi harga saham, mengingat terdapat hasil yang berbeda dari fenomena dan teori, maka diperlukan penelitian lanjutan guna memperoleh kepastian mengenai hasil penelitian.

\section{KAJIAN PUSTAKA}

Dalam penelitian ini membahas mengenai teoriteori yang digunakan antara lain teori tentang laba bersih yang berkenaan dengan rasio Profitabilitas menggunakan Return on Equity, dan Earning per Share, dilanjutkan dengan teori harga saham di pasar modal sehingga dapat menjadi dasar kerangka pemikiran dan membuat hipotesis bagi penulis. Beberapa indikator profitabilitas yang digunakan dalam penelitian ini diantaranya ialah Return On Equity dan Earning Per Share (Lukman Syamsuddin 2009:61-69).

\section{Pengertian Return On Equity}

Return On Equity (ROE) merupakan rasio untuk mengukur laba bersih setelah pajak dengan modal sendiri. Rasio ini menunjukkan efisiensi penggunaan modal sendiri dalam memperoleh laba.

Pengertian Return on Equity (ROE) menurut Brigham, Eugene F.\& Houston, Joel F (2010:149) adalah:

"Rasio akuntansi "bottom line" adalah pengembalian atas ekuitas biasa (return on common equity-ROE).
Pemegang saham berharap mendapatkan pengembalian atas uang mereka, dan rasio ini menunjukkan besarnya pengembalian tersebut dilihat dari kacamata akuntansi. ROE merupakan rasio laba bersih terhadap ekuitas biasa mengukur tingkat pengembalian atas investasi pemegang saham biasa".

Rumus menghitung Return on Equity (ROE) menurut Brigham, Eugene F \& Houston, Joel F (2010:149):

\section{ROE = Laba Bersih / Ekuitas Biasa}

Menurut Lukman Syamsudin (2002:66) mendefinisikan bahwa return on equity adalah

"Rasio untuk mengetahui seberapa besar tingkat pengembalian dana yang telah diinvestasikan dalam suatu perusahaan. Semakin tinggi tingkat ROE suatu perusahaan maka semakin baik tingkat pengembalian dari dana yang telah diinvestasikan"

Menurut Brigham and Houston (2012;150) menyatakan bahwa ada rasio yang paling penting adalah rasio pengembalian atas modal atau Return On Equity,

"Merupakan laba bersih bagi pemegang saham dibagi dengan total ekuitas pemegang saham. Setiap investor berharap mendapatkan return yang tinggi atas modal yang mereka investasikan, dan ROE menunjukan tingkat yang diperoleh, jika ROE tinggi maka harga saham juga cenderung akan tinggi. Namun jika ROE yang tinggi diperoleh melalui penggunaan utang dalam jumlah yang sangat besar, maka harga saham cenderung akan menurun."

Berdasarkan pengertian diatas dapat dikatakan jika ROE rendah maka keuntungan yang diperoleh semakin rendah sehingga harga saham turun. Begitu sebaliknya, semakin tinggi tingkat ROE maka keuntungan yang diperoleh bagi pemegang saham tinggi dan saham perusahaan tersebut akan diminati oleh investor sehingga harga saham akan naik.

\section{Pengertian Earning Per Share}

Merupakan rasio untuk mengukur keberhasilan manajemen dalam mencapai keuntungan bagi pemegang saham. Tandelilin (2001:241) mendefinisikan "Earning Per Share (EPS) sebagai perbandingan antara jumlah laba (dalam hal ini laba bersih yang siap dibagikan bagi pemegang saham) dengan jumlah saham yang beredar".

EPS = Laba Bersih / Jumlah Saham yang beredar

Semakin tinggi nilai EPS tentu saja menyebabkan semakin besar laba dan kemungkinan peningkatan jumlah dividen yang diterima pemegang saham. Hal ini akan menarik perhatian investor sehingga banyak investor membeli saham perusahaan 
tersebut yang akan berpengaruh terhadap meningkatnya harga saham.

Menurut Tryfino, (2009: 11-12) menyatakan bahwa:

Earnings per Share (EPS) adalah rasio yang digunakan untuk menghitung laba atau keuntungan bersih yang diperoleh dari selembar saham. Semakin besar EPS dapat disimpulkan bahwa kinerja perusahaan semakin efektif atau baik sehingga pada akhirnya rasio ini dapat juga digunakan untuk memprediksi pergerakan harga suatu saham. Dengan kata lain, besarnya rasio EPS mampu memberikan pengaruh terhadap harga saham.

Harga saham yang berpengaruh positif pada penelitian ini hanya dibatasi dengan membicarakan saham biasa. Apabila perusahaan menerbitkan saham biasa dan saham preferen, maka net income bagi pemegang saham biasa diperoleh dengan mengurangi net income dengan dividen dan hak-hak lainnya bagi pemegang saham preferen. Hasil yang diperoleh merupakan keuntungan yang tersedia bagi pemegang saham biasa.

Menurut Gitman (2006:13), mendefinisikan Earning Per Share (EPS) sebagai berikut :

The amount earned during on behalf of each oustanding share of common stock, calculated by dividing the period's total earnings available for the firm's common stockholder by the number of shares common stock outstanding.

Artinya jumlah yang diperoleh dari saham biasa yang beredar, dihitung dengan membagi penghasilan total periode yang tersedia bagi pemegang saham biasa perusahaan dengan jumlah saham yang beredar.

\section{Harga Saham}

Harga saham merupakan harga penutupan pasar saham selama periode pengamatan untuk tiaptiap jenis saham yang dijadikan sampel dan pergerakannya senantiasa diamati oleh para investor. Salah satu konsep dasar dalam manajemen keuangan adalah bahwa tujuan yang ingin dicapai manajemen keuangan adalah memaksimalisasi nilai perusahaan. Bagi perusahaan yang telah go public, tujuan tersebut dapat dicapai dengan cara memaksimalisasi nilai pasar harga saham yang bersangkutan. Dengan demikian pengambilan keputusan selalu didasarkan pada pertimbangan terhadap maksimalisasi kekayaan para pemegang saham.

Sartono (2008:70) menyatakan bahwa

Harga saham terbentuk melalui mekanisme permintaan dan penawaran di pasar modal. Apabila suatu saham mengalami kelebihan permintaan, maka harga saham cenderung naik. Sebaliknya, apabila kelebihan penawaran maka harga saham cenderung turun.

Menurut Jogiyanto (2008:167) pengertian dari harga saham adalah

"Harga suatu saham yang terjadi di pasar bursa pada saat tertentu yang ditentukan oleh pelaku pasar dan ditentukan oleh permintaan dan penawaran saham yang bersangkutan di pasar modal".

Menurut Brigham dan Houston (2010:7) harga saham adalah

Harga saham menentukan kekayaan pemegang saham. Maksimalisasi kekayaan pemegang saham diterjemahkan menjadi maksimalkan harga saham perusahaan. Harga saham pada satu waktu tertentu akan bergantung pada arus kas yang diharapkan diterima di masa depan oleh investor "ratarata" jika investor membeli saham.

\section{Faktor Faktor yang mempengaruhi Harga Saham}

Harga saham sering kali berfluktuasi setiap waktu karena dipengaruhi oleh beberapa faktor. Terdapat beberapa faktor yang dapat mempengaruhi fluktuasi harga saham di pasar modal, hal ini terjadi karena harga saham dipengaruhi oleh faktor eksternal dari perusahaan maupun faktor internal perusahaan. Agar tidak mendapatkan risiko kerugian yang lebih besar akibat dari pengaruh faktor tersebut,maka dari itu para pemegang saham harus mengetahui dan mempelajari dampak dari faktor tersebut.

Menurut Arifin (2001) faktor-faktor yang mempengaruhi harga saham yaitu pertama, faktor non keuangan yaitu misalnya berupa pergerakan harga tren saham, yang biasanya digunakan oleh investor untuk pengambilan keputusan membeli ataupun menjual saham. Kedua, faktor keuangan berupa informasi-informasi yang terkandung dalam laporan keuangan, misalnya profitabilitas dan rentabilitas. Informasi keuangan tersebut yang digunakan untuk mengukur kinerja perusahaan dimana kinerja perusahaan akan dijadikan acuan dari nilai saham dimata investor. Faktor keuangan disini termasuk rasio-rasio yang merupakan ukuran terhadap kinerja perusahaan.

\section{Kerangka Pemikiran}

Bagi perusahaan yang telah go public pasti bertujuan untuk memaksimalkan kekayaan pemegang saham melalui nilai perusahaan yang tercermin dalam harga saham di pasar modal. Menurut Brigham dan Houston (2010:7): "Harga saham menentukan kekayaan pemegang saham. Maksimalisasi kekayaan pemegang saham diterjemahkan menjadi memaksimalkan harga saham perusahaan. Tinggi 
rendahnya suatu harga saham akan ditentukan oleh permintaan dan penawaran pasar.

Namun disisi lain kemampuan perusahaan dalam memperoleh laba juga menjadi daya tarik bagi investor untuk membeli saham. Jika laba suatu perusahaan meningkat maka akan meningkatkan permintaan saham dan harga saham pun ikut naik. Analis fundamental mempelajari perusahaan dan membuat keputusan investasi berdasarkan faktorfaktor seperti kesehatan finansial, keunggulan kompetitif, kualitas manajemen, prospek pertumbuhan, rasio profitabilitas, rasio harga terhadap pendapatan (P / E) dan faktor makroekonomi (Info publikasi Orange County, Santa Ana, California 2014).

Menurut Lukman Syamsudin (2002:59-61) ada beberapa pengukuran profitabilitas perusahaan dimana masing-masing pengukuran dihubungkan dengan volume penjualan, total aktiva dan modal sendiri. Salah satu pengukuran rasio profitabilitas yang berhubungan dengan laba dan modal ialah return on equity (ROE), earning per share (EPS).

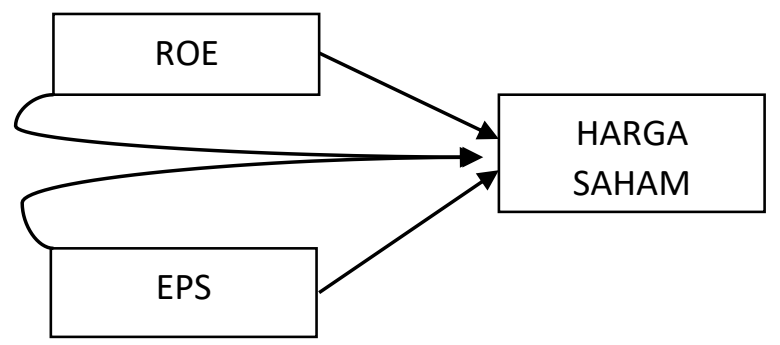

\section{Gambar 1. Kerangka Pemikiran \\ Pengaruh Return on Equity terhadap Harga saham}

Menurut Brigham and Houston (2012;150) "ada rasio yang paling penting adalah rasio pengembalian atas modal atau Return On Equity, yang merupakan laba bersih bagi pemegang saham dibagi dengan total ekuitas pemegang saham. Jika Return On Equity tinggi maka harga saham juga cenderung akan tinggi. Sejalan dengan hasil penelitian Wahyu (2015), Alwi dan Sutrisno (2013) bahwa Return on equity memiliki pengaruh terhadap harga saham karena mencerminkan efisiensi dan efektifitas perusahaan dalam mendapatkan laba bersih berdasarkan jumlah modal yang tersedia. Namun menurut Muhammad Ircham, Siti Ragil Handayani dan Muhammad Saifi (2014) menyatakan bahwa return on equity berpengaruh negatif terhadap harga saham.

\section{Pengaruh Earning Per Share terhadap Harga saham}

Menurut Husnan (2009) tingkat profitabilitas yang mampu dihasilkan oleh emiten akan mempengaruhi tingkat harga saham, kemampuan perusahaan dalam menghasilkan laba untuk lembar saham yang beredar dapat dilihat dalam rasio Earning Per Share (EPS). Sejalan dengan hasil penelitian Alwi dan Sutrisno (2013), Gabriella dan Lauw (2014) bahwa EPS berpengaruh secara signifikan terhadap harga saham. Kemudian hasil penelitian Rowland Bismark Fernando Pasaribu (2008) diperoleh hasil bahwa earning per share (EPS) merupakan variabel yang memiliki pengaruh dominan terhadap harga saham pada enam industri, sedangkan profitabilitas (SALCA) hanya dominan pada industri pertanian, sementara likuiditas (CashTA) berpengaruh dominan pada industri properti dan real estate.

\section{Hipotesis} berikut:

Maka penulis merumuskan hipotesis sebagai

H1: Return On Equity berpengaruh signifikan positif terhadap harga saham perusahaan ban pada sektor otomotif dan komponen yang terdaftar di Bursa Efek Indonesia.

$\mathrm{H} 2$ : Earning per share berpengaruh signifikan positif terhadap harga saham perusahaan ban pada sektor otomotif dan komponen yang terdaftar di Bursa Efek Indonesia.

H3: Return On Equity dan Earning Per Share secara simultan berpengaruh signifikan terhadap harga saham perusahaan ban pada sektor otomotif dan komponen yang terdaftar di Bursa Efek Indonesia.

\section{METODE PENELITIAN}

Dalam penelitan ini metode yang digunakan adalah metode analisis regresi linier berganda. Terdapat beberapa asumsi yang harus dipenuhi terlebih dahulu sebelum menggunakan Multiple Linear Regression sebagai alat untuk menganalisis pengaruh variabel-variabel yang diteliti, agar terhindar dari karakteristik-karakteristik BLUE (Best Linier Unbiased Estimate). Beberapa asumsi itu diantaranya adalah:

\section{Uji Normalitas}

Asumsi normalitas merupakan persyaratan yang sangat penting pada pengujian kebermaknaan (signifikansi)koefisien regresi. Model regresi yang baik hendaknya berdistribusi normal atau mendekati normal. 
Menurut Wing Wahyu Winarno (2011:5.37),untuk pengujian lebih akurat diperlukan alat analisis dan Eviews menggunakan dua cara, yaitu dengan histogram dan uji Jarque-bera. Jarque-bera adalah uji statistik untuk mengetahui apakah data berdistribusi normal, Jarque-Bera didistribusi dengan dengan derajat bebas (degree of freedom) sebesar 2.

\section{Uji Multikolinieritas}

Istilah multikolinieritas digunakan untuk menunjukkan adanya hubungan linear diantara independent variabel dalam regresi. Jika independent variable berkorelasi dengan sempurna, maka disebut multikolinieritas sempurna yang berarti ada hubungan linear yang "sempurna" (pasti) diantara beberapa atau semua independent variable dari model regresi.

\section{Uji Heteroskedastisitas}

Heteroskedastisitas merupakan keadaan dimana variabel dari setiap gangguan tidak konstan. Uji heteroskedastisitas dapat dilakukan dengan menggunakan White Heteroskedasticity di dalam software eviews 5 for windows. Menurut Widarjono (2007:125) : "Pengujian White Heteroskedasticity bertujuan untuk mendeteksi apakah varians dari setiap unsur error term menunjukkan suatu angka yang konstan." Untuk mendeteksi adanya heterokedastisitas dilakukan dengan menggunakan uji white.

\section{Uji Otokorelasi}

Untuk menguji ada tidaknya otokorelasi dapat dilakukan dengan menghitung nilai statistik DurbinWatson (D-W). Uji Durbin-Watson merupakan salah satu uji yang banyak dipakai untuk mengetahui ada tidaknya otokorelasi.

\section{HASIL DAN PEMBAHASAN}

Dalam penelitian ini metode yang digunakan adalah regresi linier berganda dengan pengolahan data menggunakan Eviews.

Tabel 1. Hasil Regresi Linier Berganda

\begin{tabular}{ccccc}
\hline Variable & Coefficient & $\begin{array}{c}\text { Std. } \\
\text { Error }\end{array}$ & t-Statistic & Prob. \\
\hline C & 5.61 & 0.26 & 21.47 & 0.00 \\
EPS & 0.58 & 0.10 & 5.54 & 0.00 \\
ROE & -0.47 & 0.18 & -2.52 & 0.01 \\
\hline
\end{tabular}

Dari hasil tabel diatas, diperoleh nilai persamaan regresi linier berganda sebagai berikut:

$$
\begin{gathered}
\mathrm{HS}=5.61990207+0.5868350397 * \mathrm{EPS}- \\
0.4764064509 * \mathrm{ROE}+\varepsilon
\end{gathered}
$$

C $=5.61990207 \quad$ Menunjukan jika Return On Equity dan Earning Per Share yang bernilai 0 maka harga saham bernilai 5.61990207.

$b_{1}=0.5868350397$ Menunjukan jika Earning Per Share meningkat $1 \%$ maka Harga saham akan meningkat sebesar 0.5868350397 .

$b_{2}=-0.4764064509$ Menunjukan jika Return On Equity meningkat $1 \%$ maka harga saham akan meningkat sebesar 0.4764064509 .

\section{Uji Normalitas}

Hasil uji normalitas menunjukan nilai jarque bera sebesar $1.69 \leq 2$ dan nilai probabilitas sebesar $0.42 \geq$ 0.05 , sesuai dengan kriteria yang tertera sebelumnya maka data berdistribusi normal.

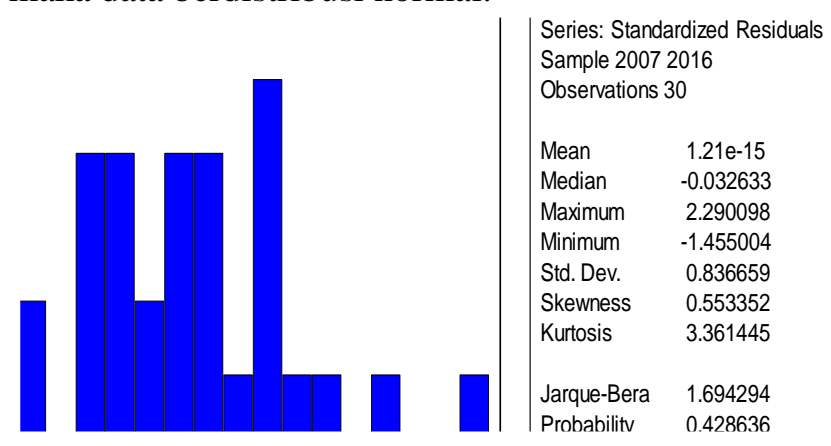

\section{Gambar 1. Output Uji Normalitas}

Uji Multikolinieritas

Berikut dibawah ini adalah hasil perhitungan uji multikolinieritas dengan melihat nilai koefisien antar variabel menggunakan Eviews 5.0:

Tabel 2. Hasil Uji Multikolinieritas

\begin{tabular}{|c|c|c|c|}
\hline & EPS & HS & ROE \\
\hline EPS & $\mathbf{1 . 0 0 0 0 0 0}$ & 0.743331 & 0.848395 \\
\hline HS & 0.743331 & $\mathbf{1 . 0 0 0 0 0 0}$ & 0.475631 \\
\hline ROE & 0.848395 & 0.475631 & $\mathbf{1 . 0 0 0 0 0 0}$ \\
\hline
\end{tabular}

Dari hasil tabel diatas tampak tidak ada koefisien korelasi yang sangat kuat antar variabel, sehingga diduga tidak adanya hubungan linier antar variabel.

\section{Uji Heteroskedastisitas}

Berikut dibawah ini adalah uji heteroskedastisitas dengan menggunakan Uji White pada Eviews 5.0 
Tabel 3. Hasil Uji Heteroskedastisitas

White Heteroskedasticity Test:

\begin{tabular}{cccc}
\hline \hline $\begin{array}{c}\text { F-statistic } \\
\begin{array}{c}\text { Obs*R- } \\
\text { squared }\end{array}\end{array}$ & 0.506325 & Probability & 0.731467 \\
\hline \hline
\end{tabular}

Berdasarkan tabel diatas terlihat nilai Obs*R-squared adalah sebesar 2.248228dan nilai probabilitasnya adalah sebesar 0.690210 (lebih besar dari $\alpha=5 \%$ ), maka dapat disimpulkan bahwa data tersebut bersifat homokedastisitas.

\section{Uji Otokorelasi}

Berikut dibawah ini adalah hasil perhitungan Durbin-

Watson menggunakan Eviews 5.0 :

Tabel 4. Hasil Uji Otokorelasi

\begin{tabular}{|c|c|c|c|}
\hline $\begin{array}{c}\text { Durbin- } \\
\text { Watson stat }\end{array}$ & 1.620086 & Prob(F-statistic) & 0.000001 \\
\hline
\end{tabular}

Berdasarkan tabel diatas telihat nilai DurbinWatson adalah sebesar 1.620086. Angka ini terletak ditengah sehingga data tersebut diatas menunjukan tidak adanya otokorelasi.

\section{Analisis Koefisien Determinasi}

Berikut dibawah ini adalah hasil perhitungan koefisien determinasi menggunakan nilai $\mathrm{R}$-square :

Tabel 5. Hasil Uji Koefisien Determinasi

\begin{tabular}{|c|c|c|c|}
\hline R-squared & 0.638284 & $\begin{array}{c}\text { Mean } \\
\text { dependent } \\
\text { var }\end{array}$ & 7.053000 \\
\hline
\end{tabular}

Berdasarkan tabel diatas terlihat nilai Rsquared sebesar 0.638284 atau $63,8284 \%$ menunjukan bahwa return on equity dan earning per share secara simultan memberikan pengaruh terhadap harga saham sebesar 63,8284\%, sedangkan sisanya $36.1716 \%$ dipengaruhi oleh variabel lain.

\section{Hasil Pengujian Hipotesis}

Uji F

Tabel 6. Hasil Uji F

\begin{tabular}{|l|c|c|c|}
\hline Log likelihood & - & F-statistic & 23.82205 \\
\hline
\end{tabular}

Berdasarkan tabel diatas, diketahui bahwa nilai $F$ hitung sebesar 23.82205. Nilai tersebut dapat dibandingkan dengan tingkat probabilitas yaitu 0.05, dari tabel distribusi $\mathrm{F}$ didapat nilai untuk $\mathrm{F}$ tabel yaitu $\mathrm{n}=30 ; \mathrm{k}=3$; df $1=\mathrm{k}-1=3-1=2 ; \mathrm{df} 2=\mathrm{n}-\mathrm{k}=30-3=27$, maka diketahui nilai $\mathrm{F}$ tabel sebesar 3,35. Dari nilai-nilai diatas dapat diketahui $\mathrm{F}$ hitung $\geq \mathrm{F}$ tabel yaitu $23.82205 \geq 3,35$, maka Ho ditolak artinya terdapat pengaruh yang signifikan antara Return On Equity (ROE) dan Earning Per Share (EPS) terhadap Harga Saham.
Uji t

Tabel 7. Hasil Uji T

\begin{tabular}{ccc}
\hline \hline Variable Coefficient & Std. \\
Error
\end{tabular} t-Statistic Prob.

\begin{tabular}{ccccc}
\hline \hline ROE & -0.476406 & 0.188314 & -2.529854 & 0.0176 \\
EPS & 0.586835 & 0.105813 & 5.545966 & 0.0000
\end{tabular}

Berdasarkan tabel diatas diperoleh hasil perhitunganuntuk variabel return on equity dan earning per share. Nilai t hitung untuk variabel return on equity adalah sebesar -2.529854 menunjukan $t$ hitung $\geq \mathrm{t}$ tabel atau $-2.529854 \geq 2,052$. Maka dapat disimpulkan bahwa Ho ditolak, Return On Equity (ROE) berpengaruh signifikan positif terhadap harga saham perusahaan ban pada sektor otomotif dan komponen yang terdaftar di Bursa Efek Indonesia.

\section{KESIMPULAN DAN SARAN}

Berdasarkan hasil penelitian dan uraian yang telah penulis paparkan, maka dapat diambil kesimpulan sebagai berikut

1. Return On Equity berpengaruh signifikan positif terhadap harga saham.

2. Earning Per share berpengaruh signifikan positif terhadap harga saham.

3. Hasil penelitian secara simultan menunjukan adanya hubungan. Besarnya kontribusi Returnon equity dan Earning per share secara simultan memberikan pengaruh terhadap harga saham sebesar $63,8284 \%$, sedangkan sisanya $36,1716 \%$

Saran dipengaruhi oleh variabel lain.

1) Bagi perusahaan agar dapat meningkatkan terus kemampuan

2) Untuk penelitian selanjutnya akan lebih baik apabila dapat mengembangkan sampel dan tahun penelitian yang lebih besar lagi.

3) Untuk penelitian selanjutnya agar menggunakan variabel yang belum diteliti. Pengembangan ini perlu dilakukan mengingat banyak hal yang berperan dalam mempengaruhi pertumbuhan laba bersih baik faktor eksternal maupun faktor internal.

\section{REFERENSI}

[1] Ajija, R Shocrul, Sari, W Dyah, Setianto, H Rahmat dan Primanti, R Martha. 2011. Cara Cerdas Menguasai Eviews. Jakarta:Salemba Empat. 
[2] Alwi Abdul, dan Sutrisno. 2013. Analisis pengaruh Faktor Fundamental terhadap harga saham perusahaan manufaktur. Proceeding Seminar Nasional dan Call For Paper Sancall. ISBN:978-979-636-147-2.

[3] Alwi, Iskandar. Z. 2003. Pasar Modal, Teori dan Aplikasi, Cetakan Pertama, Yayasan Pancur Siwah, Jakarta.

[4] Anoraga, P. Dan Puji Pakarti. 2003. Pengantar Pasar Modal. Jakarta: Rineka Cipta.

[5] Brigham and Houston. 2006. Dasar-dasar Manajemen Keuangan (10th ed). Jakarta. Salemba Empat.

[6] Brigham and Houston. 2010. Dasar-dasar Manajemen Keuangan (11th ed). Jakarta. Salemba Empat.

[7] Danika, Noer Azam, dan Hendro Sasongko. 2014. Analisis Fundamental, Teknikal dan Makro Ekonomi Harga saham Sektor Pertanian. Jurnal Manajemen dan Kewirausahaan Volume 16 No 2.

[8] Darmadji, Tjiptono \& Hendy $\mathrm{M}$. Fakhruddin. 2006. Pasar Modal di Indonesia: Pendekatan Tanya Jawab. Jakarta: Salemba Empat.

[9] Dedi Susilo, Atim Djazuli, Nur Khusniyah 2015. Pengaruh Variabel Fundamental dan Makro Ekonomi terhadap Harga saham (Studi pada perusahaan yang masuk dalam Indeks LQ45). Jurnal Aplikasi Manajemen Volume 13 No 1. SK Dirjen DIKTI No.66b/DIKTI/KEP/2011. ISSN:16935241.

[10] Desmond Wira. 2014. Analisis Fundamental Saham. Exceed. Jakarta

[11] Eduardus Tandelilin. 2010. Portofolio dan Investasi - Teori dan Aplikasi. Yogyakarta: Kanisius.

[12] Gabriella, dan Lauw. 2014. Pengaruh Earnings per Share (EPS), Return On Investment (ROI), Price to Book Value (PBV) dan Price Earnings Ratio (PER) Terhadap Harga Saham: Studi Empiris Perusahaan Sektor Makanan dan Minuman yang Terdaftar di Bursa Efek Indonesia
Periode 2010-2012. Jurnal Akuntansi Volume 6 Nomor 2. ISSN:2085-8698.

[13] Gitman, Lawrence J. 2006. Principles of Managerial Finance, Seventeenth Edition. Massachusetts addison-wesley publishing Company.

[14] Gunawan. 2011. Pengaruh Analisis Fundamental terhadap harga Saham : Studi Empiris saham syariah di Jakarta Islamic Indeks. Jurnal Wira Ekonomi Mikroskil Volume 1 Nomor 1.

[15] Hartono dan Raymundus Parulian Sitohang. 2013. Analisis Hubungan Profitabilitas dengan Pergerakan Harga Saham pada sektor usaha Perbankan. Jurnal of Applied Finance and Accounting.

[16] Jogiyanto. 2008. Teori portofolio dan Analisis Investasi. Edisi Ketiga. Yogyakarta: BPFE.

[17] Jonathan Sarwono. 2006 Metode Penelitian Kuantitatif dan Kualitatif. Yogyakarta. Graha Ilmu

[18] Kasmir. 2010. Bank dan Lembaga Keuangan Lainnya. Jakarta: PT Raja Grafindo Persada.

[19] Lukman, Syamsudin 2002, Manajemen Keuangan, Raja Grafindo Persada, Jakarta.

[20] Moh Nazir. 2011. Metode Penelitian. Cetakan 6. Bogor. Ghalia Indonesia.

[21] Muhammad Ircham, Siti Ragil Handayani dan Muhammad Saifi. 2014. Pengaruh Sturktur Modal dan Profitabilitas terhadap harga Saham : Studi pada perusahaan makanan dan minuman yang terdaftar Bursa Efek Indonesia Tahun 2009-2012. Jurnal Administrasi dan Bisnis volume 11 Nomor 1.

[22] Nurrahmah Apriyani, Wiwiek Rindayanti dan Ranti Wiliasih. 2014. Pengaruh variabel EPS dan Makroekonomi terhadap return saham Jakarta Islamic Index Sektor Pertanian. Jurnal Al-Muzara'ah Volume 3 Nomor 1. ISSN:2337-6333.

[23] Nurjanti Takarini dan Hamidah Hendrarini. 2015. Rasio keuangan dan Pengaruhnya terhadap Harga Saham Perusahaan yang terdaftar di Jakarta Islamic Index. Journal 
of Business and Banking Volume 1 Nomor 2.

[24] Putu Dina Aristya Dewi dan I.G.N.A Suaryana. 2013. Pengaruh EPS, DER, dan PBV terhadap Harga saham. E-Jurnal Akuntansi Universitas Udayana. ISSN:2302-8556.

[25] Rowland Bismark. 2008. Pengaruh Variabel Fundamental terhadap harga saham perusahaan Go Public di Bursa Efek Indonesia (BEI) periode 2003-2006. Jurnal Ekonomi dan Bisnis Volume 2 Nomor 2. ISSN:1978-3116.

[26] Safitri Indrawati dan Heru Suprihhadi. 2016. Pengaruh Profitabilitas terhadap Harga saham Emiten LQ 45 yang terdaftar Bursa Efek Indonesia. Jurnal Ilmu dan Riset Manajemen Volume 5 Nomor 2.

[27] Sapto, Rahardjo. 2001. Panduan Investasi Obligasi. Jakarta:Gramedia Widiasarana Indonesia.

[28] Suad, Husnan. 2009. Teori Portofolio dan Analisis Sekuritas. Edisi Keempat. Yogyakarta: UPP STIM YKPN.

[29] Sugiyono, 2004. Metode Penelitian Bisnis, Bandung : Alfabeta.

[30] Sunita Sukhija. 2014. Fundamental Determinants Affecting Equity Share Price of BSE - 200 Companies in India. European Journal of Business and Management Volume 6 Nomor 4. ISSN:2222-1905.

[31] Syuaib, Muslimin dan Harnida Wahyuni Adda. 2015. Pengaruh Rasio Profitabilitas pada industri perbankan yang go public terhadap harga saham di Bursa Efek Indonesia. Jurnal Ilmu Manajemen Universitas Tadulako Volume 3 Nomor 1. ISSN:2443-3578.

[32] Tan Thrie Julia dan Lucia Ari Diyani. 2015. Pengaruh Faktor Fundamental terhadap harga saham. Jurnal Bisnis dan Komunikasi Volume 2 Nomor 2. ISSN:2356-4385.

[33] Tryfino. 2009. Cara Cerdas Berinvestasi Saham. Trans Media Pustaka. Jakarta.
[34] Umi, Narimawati, Sri Dewi, A., Linna Ismawati. 2010. Penulisan Karya Ilmiah, Bekasi : Genesis.

[35] Wing Wahyu Winarno. 2011. Analisis Ekonometrika dan Statistika dengan Eviews. Edisi 3. Yogyakarta:UPP STIM YKPN.

[36] Wahyu Yulianto. 2015. Pengaruh kandungan Informasi Size perusahaan, Kebijakan hutang dan Profitabilitas terhadap Harga saham perusahaan kategori Sri Kehati yang terdaftar di Bursa Efek Indonesia (BEI) periode 2007-2013. Jurnal Inovasi Volume 11.

[37] Yuli Antina Aryani dan Zulkifli. 2016. Pengaruh Rasio Profitabilitas terhadap harga saham pada perusahaan industri logam dan sejenisnya yang terdaftar di Bursa Efek Indonesia tahun 2007 - 2011. Jurnal Akuntansi Politeknik Sekayu (ASCY) Volume IV Nomor 1.

[38] Yuni Indra Sari dan Suhermin. 2016. Pengaruh Faktor Fundamental terhadap Harga Saham pada Perusahaan Telekomunikasi. . Jurnal Ilmu dan Riset Manajemen Volume 5 Nomor7. 